\title{
Pengaruh Penerapan Sistem Mentor Terhadap Pencapaian Keterampilan Klinik Asuhan Persalinan Mahasiswa Akademi Kebidanan Muhammadiyah Cirebon
}

(Suatu Studi Eksploratif di Akademi Kebidanan Muhammadiyah Cirebon)

\author{
Nurhasanah, ${ }^{1}$ Endang Sutedja, ${ }^{2}$ Farid Husin, ${ }^{3}$ Dany Hilmanto ${ }^{4}$, Firman F. Wirakusumah, ${ }^{5}$ Herman Susanto, ${ }^{6}$ \\ Hadyana Sukandar, ${ }^{7}$ Tita Husnitawati Madjid ${ }^{8}$ \\ ${ }^{1}$ Mahasiswa Program Studi Magister Kebidanan Fakultas Kedokteran Universitas Padjadjaran \\ ${ }^{2}$ Departemen Kulit dan Kelamin Fakultas Kedokteran Universitas Padjadjaran \\ ${ }^{3}$ Departemen Obstetri dan Ginekologi Fakultas Kedokteran Universitas Padjadjaran \\ ${ }^{4}$ Departemen Ilmu Kesehatan Anak Fakultas Kedokteran Universitas Padjadjaran \\ ${ }^{5,6,8}$ Departemen Obstetri dan Ginekologi Fakultas Kedokteran Universitas Padjadjaran \\ ${ }^{7}$ Departemen Epidemiologi dan Biotatistik Fakultas Kedokteran Universitas Padjadjaran
}

\begin{abstract}
Abstrak
Sesuai dengan Kepmendiknas nomer 232/U/2000, kurikulum pendidikan diploma kebidanan terdiri dari $40 \%$ teori dan $60 \%$ praktik, sehingga proporsi praktik lebih banyak. Sistem pembelajaran praktik klinik kebidanan yang selama ini berjalan terbukti belum mampu meningkatkan keterampilan klinik mahasiswa untuk itu diperlukan pengelolaan pembelajaran praktik klinik yang efektif dan efisien. Sejumlah penelitian menyimpulkan bahwa terdapat hubungan positif antara mentoring dengan pengembangan karir, pengembangan keterampilan, serta memberikan nilai tambah pada pelaksanaan rencana ekuitas. Tujuan penelitian ini adalah penerapan sistem mentor pada pendidikan kebidanan dapat meningkatkan keterampilan klinik mahasiswa. Metode Penelitian ini merupakan penelitian analitik dengan rancangan penelitian quasi experiment dengan post test only control group design. Pengambilan sampel dilakukan dengan cara total sampling dengan subjek penelitian mahasiswa Akbid Muhammadiyah Cirebon yang mengikuti PKK I gelombang I, berjumlah 34 orang, pembimbing klinik 11 orang, pembimbing akademik sebanyak 8 orang, sehingga total sampel berjumlah 53 orang. Analisis kesetaraan responden dilakukan dengan uji chi-kuadrat, analisis bivariabel dengan uji Mann Whitney untuk menilai perbedaan penilaian terhadap sistem mentor dan sistem koordinator, uji $t$ untuk menilai perbedaan keterampilan mahasiswa, dan analisis multivariabel dengan regresi logistik untuk menilai pengaruh penerapan sistem mentor terhadap pencapaian keterampilan klinik mahasiswa.Hasil penelitian keterampilan mahasiswa dalam asuhan persalinan dengan nilai rata-rata lebih tinggi pada sistem mentor 77,76 dibandingkan sistem koordinator dengan nilai rata-rata $68,94(\mathrm{p}<0,001)$. Variabel sistem mentor mempunyai pengaruh yang paling signifikan terhadap pencapaian keterampilan klinik dengan nilai RR 28,433. Simpulan hasil penelitian, sistem mentor dinilai lebih baik dalam pencapaian keterampilan klinik mahasiswa. Sistem mentor berpengaruh 28 kali terhadap pencapaian keterampilan klinik mahasiswa.
\end{abstract}

Kata kunci : Praktik klinik, sistem mentor, pembimbing akademik, pembimbing klinik.

Korespondensi : Jl Kalitanjung Timur No 14/18 Kel./Kec. Harjamukti Kota Cirebon, mobile (0231) 487677/ HP 081324177133,e-mail khansa_noer@yahoo.com 
Nurhasanah. : Pengaruh Penerapan Sistem Mentor Terhadap Pencapaian Keterampilan Klinik Asuhan Persalinan Mahasiswa Akademi Kebidanan Muhammadiyah Cirebon

\title{
The Influence of Mentoring System Towards Students' Clinical Skill of Laboraverage at Muhammadiyah Midwifery Academy of Cirebon
}

(An Exploration Study at Midwifery Study Muhammadiyah Midwifery Academy of Cirebon)

\begin{abstract}
According to Kepmendiknas number 232/U/2000, midwifery diploma education curriculum consists of $40 \%$ and $60 \%$ practice theory, clinical practice of midwifery education system during the process of running hasn't been able to increase the skills of proven clinical students, therefore still needed in managing the clinic practice learning effectively and efficiently. The purpose this research needs to be done so that it can improve the skills of the student clinic. Method this research was an analytical research with a quasi experiment research design and post test only control group design. The subject is a student of Akbid following the PKK Cirebon Muhammadiyah I Batch I, totalling 34 people, clinic supervisor is the 11th person, academic supervisor as many as 8 people, so the total overall sample amount to 53 people. Analysis of equivalence of respondents was conducted with chi-squared test, analysis bivariabel with test Mann Whitney test for Measuring difference between assessment of academic and clinic coaching towards mentor system and coordinator, t-test for measuring difference assessment the skills of the student clinic, Multivariable analysis by regression logistics for analysis influence of mentoring system towards Students' clinical skill of laboraverage care. The results showed that there were regarding the assessment of students ' skills in the care delivery with average values higher in the system between the group of mentors and systems coordinator at 77.76 with an average value of $68.94(\mathrm{p}<0.001)$ and application of the learning mentor's system was the most powerful factor with RR 28,433. Conclusion the results of the research, there was a positive influence between the application of the system of learning with achievement skill clinic mentor students in the care of labo, and the mentor system assessment can improve students skills clinic 28 greater than the system coordinator. Thus the application of the system of mentors is extremely helpful in learning the practice of midwifery clinic
\end{abstract}

Keywords: Clinical midwifery practice learning mentors system, clinic supervisor, academic supervisor 


\section{Pendahuluan}

Tenaga kesehatan yang profesional dihasilkan oleh institusi pendidikan kesehatan yang bermutu. ${ }^{2}$ Pendidikan diploma III kebidanan merupakan bagian dari jenjang pendidikan tinggi vokasional dimana proporsi praktik lebih banyak, dan untuk mencapai tujuan tersebut diperlukan pengelolaan pembelajaran praktik klinik yang efektif dan efisien. ${ }^{3-4}$ Pembelajaran klinik kebidanan atau sering disebut sebagai Praktik Klinik Kebidanan (PKK) adalah suatu proses pembelajaran untuk melatih keterampilan peserta didik dalam memberikan asuhan kebidanan melalui pengalaman nyata yang memerlukan praktik langsung pada pasien. ${ }^{4}$ Hasil studi tentang kompetensi dan sistem legislasi tenaga kesehatan di Jawa Tengah tahun 2011 bahwa keterampilan klinik serta perilaku tenaga kesehatan masih kurang, sedangkan pengetahuan rata-rata cukup. ${ }^{1}$

Saat ini pengelolaan pembelajaran praktik klinik masih ditemukan berbagai kendala, antara lain adanya perbedaan persepsi tentang pembelajaran praktik antara pembimbing akademik dari institusi pendidikan dengan pembimbing klinik di lahan praktik, jumlah pembimbing klinik belum memadai baik kuantitas maupun kualitasnya, serta banyaknya jumlah institusi pendidikan kebidanan yang juga akan mempengaruhi ketersediaan lahan praktik. Hal ini mempengaruhi proses pembelajaran klinik, sehingga menjadi kurang optimal sehingga berdampak pada pencapaian kompetensi mahasiswa. ${ }^{7-14}$

Saat ini penanggung jawab kegiatan praktik klinik kebidanan di institusi pendidikan bidan adalah seorang koordinator. Sistem koordinator pada praktik klinik kebidanan yang selama ini berjalan terbukti belum mampu meningkatkan keterampilan klinik mahasiswa. Kendala yang dijumpai selama praktik klinik tidak mampu diatasi dengan baik, karena koordinator hanya berperan mengkoordinir kegiatan praktik klinik sampai dengan memperoleh nilai hasil evaluasi, sedangkan proses bimbingan mahasiswa bergantung pada pembimbing akademik (PA) dan pembimbing klinik (PK).

Idealnya terjalin suatu kerjasama yang dinamis dan profesional antara pembimbing akademik (PA) dengan pembimbing klinik (PK) selama proses praktik klinik kebidanan. Peran tersebut dapat dilakukan oleh seorang mentor. karena mentor dapat berperan sebagai pemberi dukungan, pelatih, penasehat, pemandu, teladan, penyokong, dan pengajar. Peran mentor dalam membangun praktik klinik dapat menciptakan koordinasi yang baik antar pembimbing akademik dan pembimbing klinik, sehingga terjalin kerjasama dan komunikasi yang dinamis diantara mereka, penerapan sistem mentor, diharapkan terbangun persamaan persepsi antara pembimbing akademik, pembimbing klinik dan mahasiswa dalam proses bimbingan klinik. Hasilnya diasumsikan dapat meningkatkan keterampilan klinik mahasiswa. Pengaruh mentoring terhadap kepuasan kerja, konflik peran dan prestasi kerja pernah diteliti oleh Dwi Cahyono dengan hasil mentoring berpengaruh positif terhadap peningkatan prestasi kerja dan kepuasan kerja. ${ }^{6}$

\section{Metode}

Penelitian ini menggunakan rancangan quasi experiment dengan post test only control group design dan dilakukan dengan menerapkan sistem mentor terhadap pembelajaran praktik klinik kebidanan dan sistem koordinator sebagai kelompok kontrol. Variabel terikat adalah keterampilan klinik mahasiswa dalam asuhan persalinan, dan variabel perancu adalah nilai UAS asuhan persalinan dan nilai ujian laboratorium asuhan persalinan.

Subjek pada penelitian ini adalah seluruh mahasiswa semester IV Akademi Kebidanan Muhammadiyah Cirebon sesuai dengan kriteria penelitian. Subjek penelitian yang lain adalah pembimbing akademik dari akademi kebidanan Muhammadiyah Cirebon dan pembimbing klinik dari rumah sakit tempat praktik total subjek penelitian adalah 53 responden. Penelitian ini dilaksanakan pada PKK I selama 5 minggu (gelombang I) yaitu pada bulan Mei-Juni 2013. Instrument yang digunakan untuk mengukur penilaian sistem praktik klinik adalah kuesioner, dan untuk mengukur penilaian keterampilan mahasiswa adalah daftar tilik. ${ }^{15}$

Data hasil penelitian dianalisis dengan uji Chi-Square untuk menganalisis kesetaraan antara karakteristik mahasiswa, pembimbing klinik dan pembimbing akademik. Uji Mann-Whitney untuk menganalisis perbedaan penilaian pembimbing akademik dan pembimbing klinik pada praktik klinik. Uji $t$ untuk mengukur perbedaan penilaian keterampilan klinik mahasiswa. Uji regresi

IJEMC, Volume 1 No. 1, Desember $2014 \mid \mathbf{3}$ 
Nurhasanah. : Pengaruh Penerapan Sistem Mentor Terhadap Pencapaian Keterampilan Klinik Asuhan Persalinan Mahasiswa Akademi Kebidanan Muhammadiyah Cirebon

logistik untuk mengetahui faktor-faktor yang paling berpengaruh terhadap pencapaian keterampilan klinik. Analisis interaksi untuk menilai variabel perancu. ${ }^{18-20}$
Hasil

Berdasarkan hasil analisis kesetaraan baik dari mahasiswa, pembimbing klinik dan pembimbing akademik antara kelompok sistem mentor dan kelompok sistem koordinator menunjukkan nilai $\mathrm{p}>0,005$ sehingga layak diperbandingkan.

Tabel 1 Karakteristik Subjek Penelitian

\begin{tabular}{|c|c|c|c|c|}
\hline \multirow{2}{*}{\multicolumn{2}{|c|}{ Karakteristik }} & \multicolumn{2}{|c|}{ Kelompok } & \multirow[b]{2}{*}{ Nilai $p$} \\
\hline & & $\begin{array}{c}\text { Sistem } \\
\text { coordinator }\end{array}$ & Sistem mentor & \\
\hline & 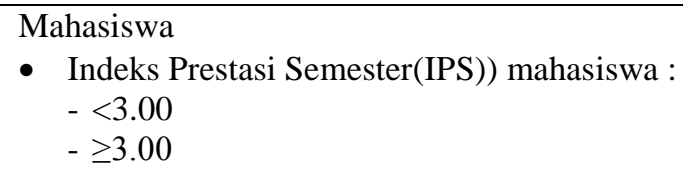 & $\begin{array}{c}\mathrm{n}=17 \\
3 \\
3 \\
14\end{array}$ & $\begin{array}{c}\mathrm{n}=17 \\
3 \\
3 \\
14\end{array}$ & 1,00 \\
\hline 2. & $\begin{array}{l}\text { Pembimbing Akademik (PA) } \\
\begin{array}{l}\text { - Pendidikan Terakhir } \\
-\quad \text { D4 } \\
-\quad \text { S2 } \\
\text { - Pengalaman menjadi PA } \\
-<2 \text { tahun } \\
-\geq 2 \text { tahun }\end{array}\end{array}$ & $\begin{array}{c}\mathrm{n}=4 \\
4 \\
0 \\
0 \\
4\end{array}$ & $\begin{array}{c}\mathrm{n}=4 \\
4 \\
0 \\
0 \\
4\end{array}$ & - \\
\hline 3 & 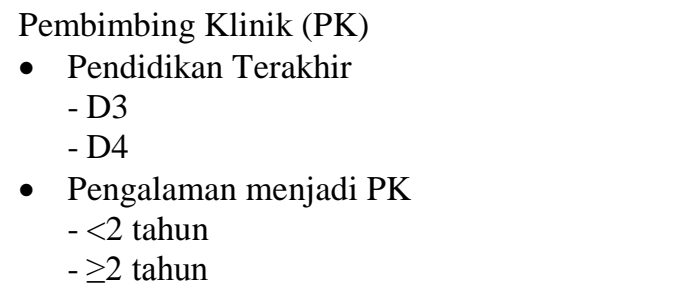 & $\begin{array}{r}n=6 \\
4 \\
2\end{array}$ & $\begin{array}{r}n=5 \\
4 \\
1\end{array}$ & 1,00 \\
\hline
\end{tabular}

Ket *) Uji Chi-Square

Karakteristik secara keseluruhan pada kedua kelompok (kelompok sistem mentor dan perbedaan karakteristik sehingga kedua kelompok sistem koordinator) tidak ada

Tabel 2 Perbedaan penilaian pembimbing akademik (PA) dan pembimbing klinik (PK) pada sistem mentor dan sistem koordinator

\begin{tabular}{lccc}
\hline \multirow{2}{*}{\multicolumn{1}{c}{ Penilaian }} & \multicolumn{2}{c}{ Sistem Praktik klinik } & \multirow{2}{*}{ Nilai p* } \\
\cline { 2 - 3 } & $\begin{array}{c}\text { Sistem } \\
\text { Koordinator }\end{array}$ & $\begin{array}{c}\text { Sistem } \\
\text { Mentor }\end{array}$ & \\
\hline $\begin{array}{l}\text { Pembimbing Akademik } \\
\text { Median }\end{array}$ & 30 & 85 & 0,017 \\
$\begin{array}{l}\text { Rentang } \\
\text { Pembimbing Klinik }\end{array}$ & $20-45$ & $80-85$ & \\
$\begin{array}{l}\text { Median } \\
\text { Rentang }\end{array}$ & 20 & 80 & 0 \\
\hline
\end{tabular}

Ket *) Uji Mann-Whitney 
Nurhasanah. : Pengaruh Penerapan Sistem Mentor Terhadap Pencapaian Keterampilan Klinik Asuhan Persalinan Mahasiswa Akademi Kebidanan Muhammadiyah Cirebon

Tabel 3 Perbedaan penilaian keterampilan klinik mahasiswa dalam asuhan persalinan pada sistem mentor dan sistem koordinator

\begin{tabular}{|c|c|c|c|c|c|c|c|c|c|}
\hline \multirow{3}{*}{$\begin{array}{c}\text { Sistem praktik } \\
\text { klinik }\end{array}$} & \multicolumn{8}{|c|}{ Keterampilan klinik mahasiswa } & \multirow{3}{*}{ Nilai $\mathbf{p}^{*}$} \\
\hline & \multirow[b]{2}{*}{$\begin{array}{l}\text { Rata- } \\
\text { rata }\end{array}$} & \multirow[b]{2}{*}{ SD } & \multirow[b]{2}{*}{ Rentang } & \multicolumn{2}{|c|}{ Kurang } & \multicolumn{2}{|c|}{ Baik } & Jumlah & \\
\hline & & & & $\mathbf{n}$ & $\%$ & $\mathbf{n}$ & $\%$ & $\mathbf{N} \%$ & \\
\hline Koordinator & 68,94 & 7,0 & $57-81$ & 11 & 65 & 6 & 35 & 17100 & \\
\hline Mentor & 77,76 & 3,7 & $69-83$ & 1 & 6 & 16 & 84 & 17100 & $<0,001$ \\
\hline
\end{tabular}

Ket *) Uji $t=4,611$

Pencapaian keterampilan antara kedua kelompok sistem mentor dan sistem koordinator dengan hasil terdapat perbedaan yang signifikan, hal ini dapat dilihat di tabel 3 bahwa kelompok sistem mentor mendapat rata-rata nilai keterampilan mahasiswa dalam asuhan persalinan lebih tinggi yaitu 77,72 sedangkan kelompok sistem koordinator yaitu 68,94 dengan nilai $\mathrm{p}<0,001$
Berkaitan dengan adanya kenaikan nilai pencapaian keterampilan mahasiswa dalam asuhan persalinan, hal ini didukung adanya perbedaan penilaian dari pembimbing akademik (PA) dan pembimbing klinik (PK) terhadap sistem pembelajaran antara kelompok mentor dan kelompok koordinator dapat dilihat pada tabel 2 dengan skor median dan skor rentang sistem mentor lebih besar.

Tabel 4 Faktor-faktor yang berpengaruh terhadap pencapaian keterampilan klinik asuhan persalinan mahasiswa

\begin{tabular}{lcccc}
\hline Variabel & Koef B & SE $(\beta)$ & Nilai p* & RR (IK 95\%) \\
& & & & \\
\hline Model Awal & & & & \\
- Sistem mentor & 3,028 & 1,372 & 0,027 & $20,66(1,40-303,86)$ \\
- Nilai UAS Asuhan Persalinan & 0,725 & 1,147 & 0,527 & $2,06(0,22-19,56)$ \\
- Nilai ujian laboratorium keterampilan & 2,503 & 1,276 & 0,050 & $12,22(1,00-149,07)$ \\
$\quad$ klinik asuhan persalinan & & & & \\
Model Akhir & 3,348 & 1,305 & 0,010 & $28,43(2,20-367,05)$ \\
Sistem mentor & 2,598 & 1,252 & 0,038 & $13,43(1,155-156,25)$ \\
Nilai UAS Asuhan PersalinaN & $-8,371$ & & & \\
Konstanta & & & \\
\hline
\end{tabular}

Ket *) Uji regresi logistik

Hasil analisis diatas dapat diketahui bahwa variabel yang mempunyai pengaruh signifikan adalah pembelajaran praktik klinik sistem mentor dengan nilai RR sebesar 28,43.

\section{Pembahasan}

Berbagai kompetensi diharapkan bisa dicapai oleh mahasiswa setelah mahasiswa melaksanakan praktik klinik kebidanan dan diharapkan peningkatan kualitas pembelajaran klinik baik dari institusi dan lahan praktik, sehingga mahasiswa kebidanan bergantung pada institusi pendidikan untuk memperoleh kesempatan praktik klinik yang berkualitas.

Pada penelitian ini dibangun suatu sistem praktik klinik dimana tujuannya adalah pencapaian keterampilan klinik mahasiswa lebih baik, dijelaskan dalam pencapaian keterampilan antara kedua kelompok sistem mentor dan sistem koordinator dengan hasil terdapat perbedaan yang signifikan, dimana kelompok sistem mentor yang mendapat ratarata nilai keterampilan mahasiswa dalam asuhan 
persalinan lebih tinggi yaitu 77,72 sedangkan kelompok sistem koordinator yaitu 68,94 dengan nilai $\mathrm{p}<0,001$ dalam hal ini dapat di katakan bahwa sistem pembelajaran dengan sistem mentor dapat mempengaruhi pencapaian keterampilan klinik dalam asuhan persalinan. Berkaitan dengan adanya kenaikan nilai pencapaian keterampilan mahasiswa dalam asuhan persalinan, hal ini didukung adanya perbedaan penilaian dari pembimbing akademik (PA) dan pembimbing klinik (PK) terhadap sistem pembelajaran antara kelompok mentor dan kelompok koordinator (tabel 2) dengan skor median dan skor rentang sistem mentor lebih besar. Permasalahan pada pembelajaran praktik disampaikan oleh Pusdiknakes (2011) bahwa beberapa permasalahan yang terdapat dalam pembelajaran praktik klinik, diantaranya: ${ }^{2}$

Mahasiswa mendapatkan pengawasan yang minim meliputi tidak ada umpan balik dan penilaian, tidak ada kesempatan diskusi tentapng rasional dan pengambilan keputusan klinis, tidak ada diskusi dan klarifikasi tujuan belajar, kurangnya contoh model, hak klien diabaikan.

Staf klinik (bidan) yang berganti-ganti meliputi kurangnya dalam monitoring kemajuan belajar, tidak adanya konsistensi dalam praktik klinis, kurang adanya komunikasi diantara anggota staff, tidak terdapat komunikasi yang konsisten antara prodi dan tempat praktik, staff tidak dipersiapkan sebagai preceptor. Gap dalam praktik yaitu kesulitan mengimplementasikan pengetahuan serta kerterampilan baru. Rotasi yang sering meliputi perkembangan mahasiswa tidak dapat diikuti, waktu praktik dihabiskan untuk orientasi dan adaptasi, mahasiswa tidak akrab dengan staf dan lingkungan belajar berdampak pada situasi belajar kurang baik. Lokasi tempat praktik tidak mencerminkan tempat kerja lulusan meliputi mahasiwa tidak dapat mengembangkan kompetensi yang relevan dengan pekerjaan dimasa yang akan datang.

Sebagai pemecahan permasalahan diatas penerapan sistem mentor dinilai mampu meningkatkan pencapaian keterampilan klinik mahasiswa dan membantu mahasiwa beradaptasi, mengintegrasikan teori pada pelayanan kesehatan, membatu rasa percaya diri dengan saling bertukar pengetahuan dan kemampuan klinis, membantu meningkatkan komunikasi yang dinamis dan professional antara institusi pendidikan dengan lahan praktik sehingga kemajuan keterampilan mahasiswa terpantau. ${ }^{16}$ Hal tersebut sejalan pula dengan Pusdiknakes (2011) bahwa kunci pembelajaran praktik klinik yang efektif salah satuanya adanya suatu sistem yang mendukung seluruh rangkaian proses pembelajaran klinik. Selain analisis diatas, dilakukan juga analisis faktor yang berhubungan dengan pencapaian keterampilan klinik mahasiswa dalam asuhan persalinan.

Penilaian pembimbing akademik dan pembimbing klinik pada sistem mentor lebih baik dari sistem koordinator. Hal ini sejalan dengan penilaian keterampilan mahasiswa dalam asuhan persalinan pada sistem mentor yang juga lebih baik dari sistem koordinator, dan pada penerapan sistem mentor dalam pembelajaran praktik klinik dinilai berpengaruh positif meningkatkan pencapaian keterampilan klinik mahasiswa dalam asuhan persalinan 28,43 kali.

\section{Simpulan}

Simpulan hasil penelitian ini yaitu, sistem mentor dinilai lebih baik dalam pencapaian keterampilan klinik mahasiswa. Sistem mentor berpengaruh 28 kali terhadap pencapaian keterampilan klinik mahasiswa.

\section{Daftar Pustaka}

1. Yanti WH, editor. OSCA Panduan Praktis menghadapi UAP D III Kebidanan. Yogyakarta: Mitra Cendikia; 2008.

2. Pusdiknakes, editor. Panduan Pembelajaran Praktik Klinik Kebidanan dengan Pendekatan Preceptorship dan mentorship. Jakarta: Pusdiknakes; 2011.

3. Depkes RI BP, editor. Standar Pembelajaran Praktik Kebidanan. Jakarta: Badan Pengembangan dan Pemberdayaan SDM Kesehatan; 2006.

4. Kemal N.S. Anne H TR, Ali Z, Yumiarni I. Pedoman Pelaksanaan Penguatan Pembelajaran Klinik Bagi Mahasiswa Kebidanan. United For International Development. 2003.

5. Kemal N.S. Anne H TR, Ali Z, Yumiarni I. Laporan Penilaian Program Preseptor-Mentor pada Prodi Kebidanan Poltekes Bandung,. United for International Development. 2000;7.

6. Cahyono D. Pengaruh Mentoring Terhadap Kepuasan Kerja, Konflik peran dan Prestasi Kerja Serta Niatan Untuk Pindah. 2005.

7. Ideh FZ. Nursing-Midwifery Student and Teachers' View of effective factor in clinkal education. 2012;47.

8. Wimmers PF, Schmidt,H.G.\&Splinter,T.A. Influence of Clerkship Experiences on Clinical 
Nurhasanah. : Pengaruh Penerapan Sistem Mentor Terhadap Pencapaian Keterampilan Klinik Asuhan Persalinan Mahasiswa Akademi Kebidanan Muhammadiyah Cirebon

Competence. Medical education. 2006;40:450-8.

9. Levy LS. Clinical Instructor Characteristics, Behaviors and Skills in Allied Health Care Settings: A Literature Review. Athletic Training Education Journal. 2009;4:8-13.

10 Azad Rahmani VZ, Farahnaz Abdullah zadeh. Clinical learning environment in viewpoint of nursing students in Tabriz University of Medical Sciences. Iranian Journal of Nursing and Midwifery Research. 2011;16:253-6.

11. Dunn SV, Burnett. The development of a clinical learning environment scale. Journal of Advanced Nursing. 1995;22:1166-73.

12. Dian Apriliana Rahmawatie GRR, Titi Savitri Prihatiningsih. Persepsi Mahasiswa terhadap Kualitas Supervisi Klinik di 12 Rumah Sakit Jejaring FK Unissula. Kedokteran dan Kesehatan. 2011;3:135-49.

13. Spencer J. ABC of learning and teaching in medicine: Learning and teaching in the clinical environment. BMJ. 2003;326:591-4.
14. Hutchinson L. ABC of teaching and learning:Educational Environtment. BMJ. 2003;326:810-2.

15. Depkes RI BP, editor. Pelatihan Keterampilan Melatih, . Jakarta: Depkes; 2003.

15. Seu Lennox JSMF. Mentorship, preceptorship and clinical supervision: Three key processes for supporting midwives. New Zealand Collefe Of Midwives. 2008;39:7-12.

16. Emil Huriani HM. Mentorship Sebagai Suatu Inovasi Metode Bimbingan Klinik dalam Keperawatan. 2006.

17. Dahlan MS. Statistik untuk kedokteran dan kesehatan. Jakarta: Salemba Medika; 2011.

18. Sastroasmoro S. Dasar - Dasar Metodologi Penelitian Klinis. Jakarta: Sagung Seto; 2012.

19. Satari HM WF, editor. Konsistensi Penelitian. Bandung: Resika Aditama; 2012. 